\title{
Stress-Strain Constitutive Material Models for Hybrid Steel Fiber Reinforced Concrete
}

\author{
Mohammad Jamshidi Avanaki, Mohammad Abedi, Abdollah Hoseini \\ School of Civil Engineering, College of Engineering, University of Tehran, 14155-6457, Tehran, Iran \\ Email:moh.jamshidi@ut.ac.ir
}

Received: 10 January 2020; Accepted: 10 February; Available online: 31 March 2020

\begin{abstract}
Recent advancements in fiber reinforced concrete (FRC) technology has led to the development of fibrous concrete composites, comprised of fibers with different material and/or geometry, commonly known as hybrid FRC. In one type of hybrid FRC composites, advantageous behaviors of fibers of the same material but with different geometries are gathered in a single FRC mix. The aim of this paper is to develop and validate stressstrain relationships for hybrid steel FRC composites. Six different steel FRC mixes are produced and characterization tests are conducted. Cube, cylindrical and beam specimens are produced for each characterization test corresponding to each of the Steel FRC (SFRC) composites. In this regard, an experimental program is performed to determine the basic engineering properties of SFRC composites using standard compressive, splitting tensile and three-point bending tests. The prescribed procedure of the RILEM guideline, originally developed for non-hybrid FRC, is followed using the obtained experimental results to develop stress-strain behavior models for the SFRC mixes. To validate results for the hybrid SFRC composites, numerical simulations of the 3-point bending tests were performed and compared to that of corresponding experimental results. The results indicated that the proposed stress-strain relationships yield acceptable results for characterizing the behavior of hybrid SFRC composites.
\end{abstract}

Keywords: Hybrid fiber reinforced concrete; Micro steel fiber; Macro steel fiber; Three-point bending test; Stressstrain relationship.

\section{Introduction}

The properties of a concrete mix can be enhanced by adding various additives or components. Introduction and usage of fibrous materials to strengthen mortar matrix, i.e. primarily decrease crack development and propagation, dates back to centuries ago [1]. In modern construction practice, fibers of different materials (steel, carbon, glass, polypropylene, ...) are used to increase the post-crack tensile strength and flexural properties of the concrete mortar [1-3], known as Fiber Reinforced Concrete (FRC). The design framework for fiber reinforced concrete structural elements are standardized and introduced in recent design codes and regulations [4-6]. Different fibers are usually employed to meet different requirements, various loading conditions [7-11].

The idea to use steel fibers as the main reinforcement mechanism in replacement of reinforcing bars in concrete segmental tunnels, i.e. Steel FRC (SFRC) segments, has been investigated in various research efforts[12-14] and practiced in numerous projects worldwide[14]. It has been shown that fibers improve both structural[15-17] and durability[18] of the segmental tunnel. Studies on the performance of FRC tunnels are mainly focused on loading conditions normally experienced from the tunnel assembly phase (e.g. TBM jack loads[19]) to the operational phase (e.g. symmetric ground pressures, static water pressures, so on).

Recent advancements in fiber reinforced concrete (FRC) technology has led to the development of fibrous concrete composites, comprised of fibers with different material and/or geometry, commonly known as hybrid FRC. Hybrid FRC is classified into two general types: (1) hybrid composites using fibers of different materials[18, 20-22], and (2) hybrid composites using fibers of the same material but with different geometries (length, end shape). Previous studies on hybrid composites were mainly focused on cement paste or mortar. However, research on developing exact proportions and methods for combining various fibers to produce and maximize synergistic response is on the agenda [17, 23, 24].

The current design codes require evaluation of the basic mechanical properties of the FRC composites, including compressive, splitting tensile and flexural strength, to characterize the material behavior for structural applications. The main objective is to obtain the material behavior curves, i.e. stress-crack opening or stress-strain, to be used in the structural design. 
The aim of this paper is to develop and validate stress-strain behavior models for Hybrid SFRC (HSFRC), comprised of six different combinations of steel fiber in terms of volume fraction, size and shape, using the RILEM TC 162-TDF guidelines [5]. These fundamental relationships are necessary to design structures made of hybrid SFRC, and be used for reliably assessing the structural response of in a numerical approach. For tunnel linings located in aggressive environments [15], cracking can lead to deficiencies in tunnel durability and operational performance, imposing excess maintenance costs. To this end, an experimental program including compressive, splitting tensile, and three-point bending tests (3PBTs), is conducted to assess the basic mechanical properties of the SFRC composites.

In this paper, hybrid composites using $0.3 \%$ and $0.5 \%$ volume content of micro and macro size steel fibers is investigated. This paper is part of an extensive research on the application of steel FRC in segmental lining of tunnels. The two fiber volume contents, i.e. $0.3 \%$ and $0.5 \%$, was chosen based on previous efforts to possibly replace traditional steel reinforcement with steel FRC in tunnel segments [14,25].

\section{Experimental program}

A summary of the conducted experimental program is presented here. Mechanical and geometric properties of the steel fibers used are presented in Table 1 and Fig. 1. The SFRC composites and corresponding volume content of each type of fiber is tabulated in Table 2.

Table 1. Mechanical and geomteric properties of the steel fibers used

\begin{tabular}{lllllll}
\hline Fiber type & Geometry & $\begin{array}{l}\text { Length } \\
\text { (mm) }\end{array}$ & $\begin{array}{l}\text { Diameter } \\
\text { (mm) }\end{array}$ & $\begin{array}{l}\text { Aspect } \\
\text { Ratio }\end{array}$ & $\begin{array}{l}\text { Tensile } \\
\text { strength } \\
\text { (MPa) }\end{array}$ & $\begin{array}{l}\text { Elastic } \\
\text { modulus } \\
\text { (GPa) }\end{array}$ \\
\hline Macro steel fiber & Hooked & 50 & 0.80 & 62.5 & 1169 & 210 \\
Micro steel fiber & Smooth & 13 & 0.17 & 76.5 & 2100 & 210 \\
\hline
\end{tabular}

Table 2. Fiber volume content (in \%) of SFRC mixes

\begin{tabular}{lllllll}
\hline SFRC Mix No. & $\mathbf{1}$ & $\mathbf{2}$ & $\mathbf{3}$ & $\mathbf{4}$ & $\mathbf{5}$ & $\mathbf{6}$ \\
\hline Macro steel fiber & 0.5 & - & 0.3 & 0.5 & 0.5 & 0.3 \\
Micro steel fiber & - & 0.5 & 0.3 & 0.5 & 0.3 & 0.5 \\
\hline
\end{tabular}
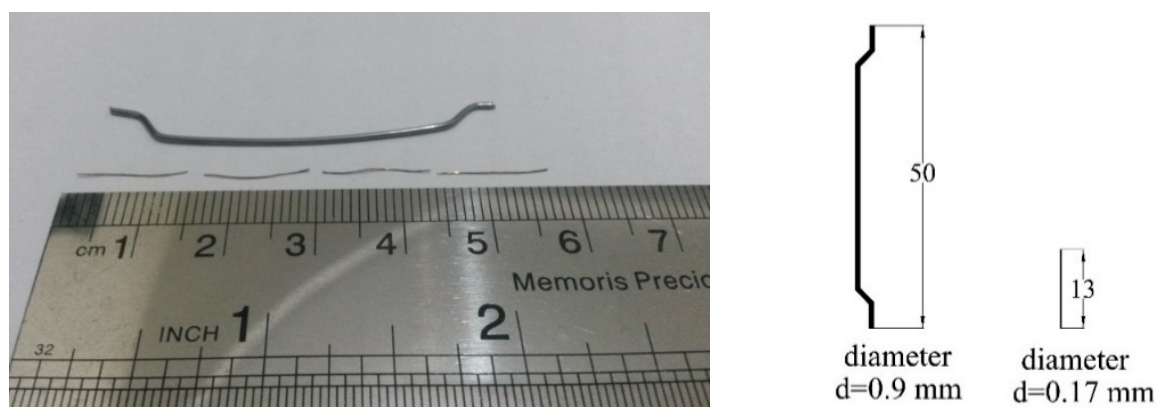

Fig. 1. The Macro and Micro steel fibers used

In all concrete mixes, the following materials and proportions were constantly used (Table 3): $400 \mathrm{~kg} / \mathrm{m} 3 \mathrm{of}$ type II Portland Cement, $1172 \mathrm{~kg} / \mathrm{m} 3$ of natural sand, $631 \mathrm{~kg} / \mathrm{m} 3$ of 5-19mm gravel and $150 \mathrm{~kg} / \mathrm{m} 3$ of tap water. Oven dried aggregates with allowance for absorption, i.e. $2.9 \%$ for sand and $2.0 \%$ for gravel, was used. The mean compressive strength of the plain (no reinforcement) concrete at 28 days was set at $40 \mathrm{MPa}$.

Table 3. Mix design of all SFRC composites

\begin{tabular}{|c|c|c|c|}
\hline Portland Cement type II (kg/m³) & Natural sand $\left(\mathrm{kg} / \mathrm{m}^{3}\right)$ & Gravel $\left(\mathrm{kg} / \mathrm{m}^{3}\right)$ & Water-Cement ratio \\
\hline 400 & 1172 & 632 & 0.375 \\
\hline
\end{tabular}

Each concrete mix was sufficient for casting the following specimens:

1) Two compressive test specimens (150x150 mm cubes).

2) Two splitting tensile test specimens $(150 \times 300 \mathrm{~mm}$ cylinders $)$.

3) Three flexural test (3PBT) specimens $(150 \times 150 \times 550 \mathrm{~mm}$ beams, $500 \mathrm{~mm}$ effective span).

The concrete specimens were cured for 28 days before carrying out the tests. Cube and cylinder specimens were used for compressive and tensile strength tests, respectively, according to relevant ASTM standards[26, 27]. 
In the 3PBT method, a notched beam of fiber reinforced concrete with simple support at the ends is tested under three-point loading to evaluate the tensile behavior of SFRC. Each beam is notched along the beam width and at the midspan tensile face using wet sawing [28] (see Fig. 2).

Deflection at beam midspan and the applied load was continuously recorded during the 3PBTs to obtain loaddeflection curves. Based on RILEM[28], a displacement control loading strategy (measured deflection at beam midspan increases at a constant rate of $0.2 \mathrm{~mm} / \mathrm{min}$ ) is used to obtain load-deflection values up to beam failure.
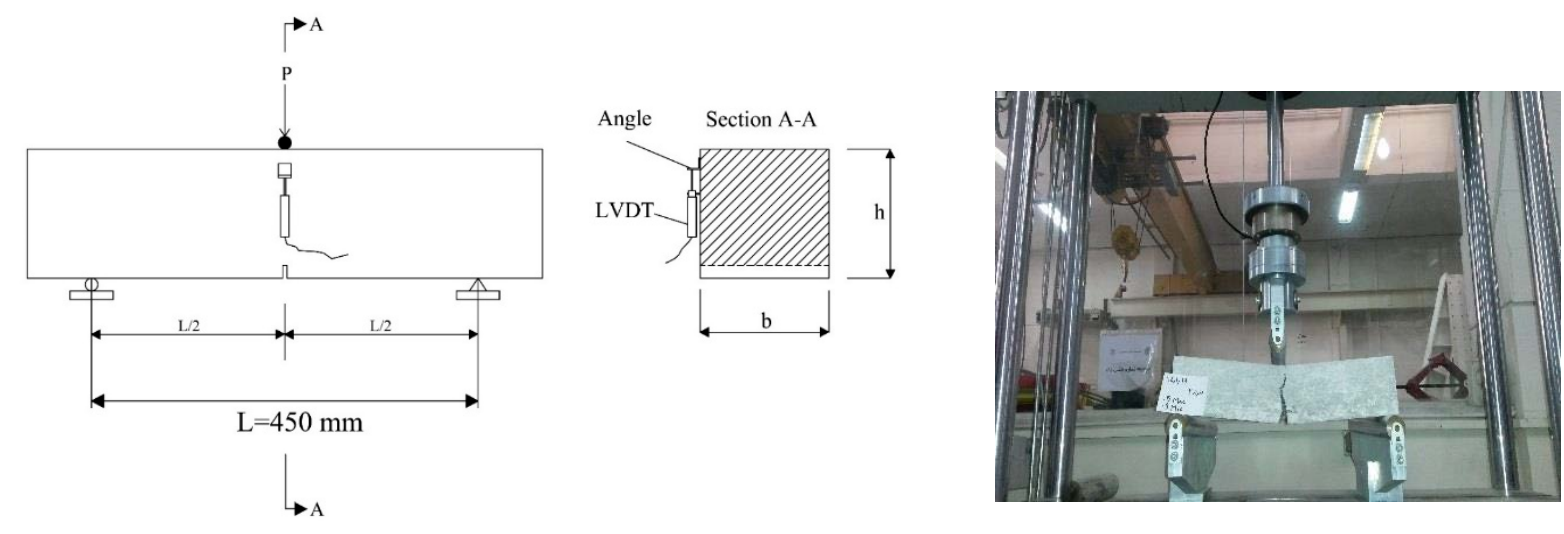

Fig. 2. Setup for three-point bending tests

Table 4 displays values of mean compressive $\left(f_{c m}\right)$ and splitting tensile $\left(f_{c t m, i}\right)$ strength, with corresponding values of coefficient of variation of the results (CV) in parantheses, along with slump values of the SFRC composites. Before adding fibers to the mix, the slump value of the fresh plain concrete was around $10-15 \mathrm{~cm}$ in almost all mixes. After adding the fibers, the slump sharply reduced from 40 to $60 \%$ in different composites. It should be noted; high energetic vibration was used to overcome low workability of the mixtures in the casting process.

The results show a rise of up to nearly 38 and $75 \%$ in compressive and tensile strengths, respectively, compared to plain concrete, due to presence of fibers. The micro fibers showed higher influence on improving compressive and tensile strengths of the SFRC mixtures. In this regard, the hybrid mixtures displayed a more distinct enhancement in strength values due to synergetic effects.

Table 4. Mean compressive and tensile strength values and corresponding $C V$ (\%)

\begin{tabular}{llllll}
\hline $\begin{array}{l}\text { Mix } \\
\text { no. }\end{array}$ & $\begin{array}{l}\text { Macro steel fiber } \\
\text { ratio (\%) }\end{array}$ & $\begin{array}{l}\text { Micro steel } \\
\text { fiber ratio (\%) }\end{array}$ & $\begin{array}{l}\text { Slump } \\
\text { (cm) }\end{array}$ & $\begin{array}{l}\text { Compression strength } \\
\text { (MPa) }\end{array}$ & $\begin{array}{l}\text { Tensile Strength } \\
\text { (MPa) }\end{array}$ \\
\hline 1 & 0.5 & - & $7-9$ & $46.44(4.82)$ & $4.23(4.24)$ \\
2 & - & 0.5 & $5-7$ & $68.83(5.91)$ & $5.21(6.86)$ \\
3 & 0.3 & 0.3 & $5-7$ & $58.25(0.70)$ & $4.66(0.64)$ \\
4 & 0.5 & 0.5 & $4-6$ & $60.83(3.29)$ & $6.69(4.61)$ \\
5 & 0.5 & 0.3 & $5-7$ & $54.02(2.49)$ & $5.49(3.29)$ \\
6 & 0.3 & 0.5 & $5-7$ & $65.61(2.25)$ & $5.04(2.21)$ \\
\hline
\end{tabular}

\section{Developing $\sigma-\varepsilon$ relationships for hybrid SFRC}

\subsection{RILEM guidelines on $\sigma-\varepsilon$ Relationship of SFRC}

The load-deflection curves obtained from the 3PBTs was employed to develop stress-strain constitutive relationships of the SFRC composites according to the RILEM TC-162 TDF [5] procedure. In this regard, Figure 3 displays the proposed tensile and compressive behavior branches for FRC. The robustness and reliability of these guidelines for hybrid FRC composites has not been proven. To this end, a numerical study is conducted to validate the derived stress-strain relationships for the hybrid SFRC composite.

\subsection{Load-deflection relationships}

Mean failure loads from three-point bending tests of the SFRC mixes are gathered in Table 5. In Figures 4-7, the obtained mean load-deflection curves from the 3PBTs for the different SFRC composites is presented. It should be noted, the "Mic.” and "Mac.” abbreviations refer to Micro and Macro steel fiber, respectively. Average values of maximum and residual flexural strength values, along with corresponding Coefficients of Variation (CV), for each SFRC mix is presented in Table 6 [28]. 


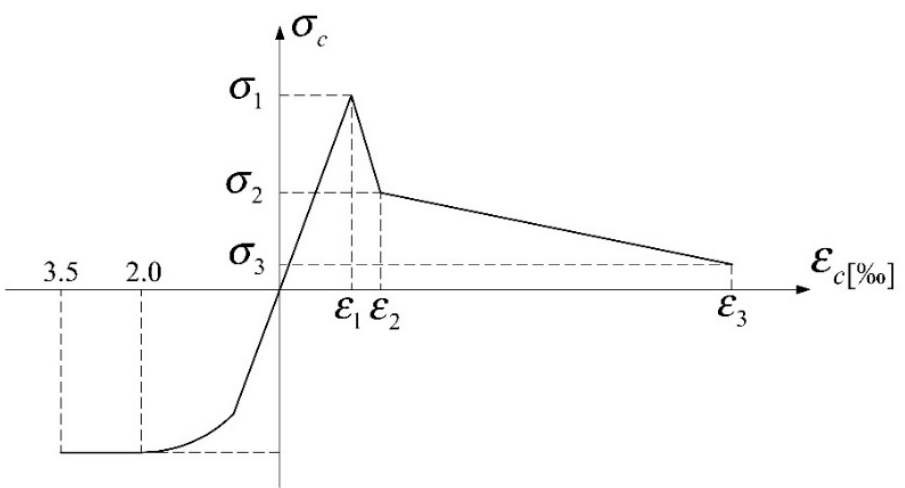

$\sigma_{1}=0.7 f_{f c t m, f l}(1.6-d)\left(d\right.$ in m) $\left(\mathrm{N} / \mathrm{mm}^{2}\right) ; \sigma_{2}=0.45 f_{R, 1} \kappa_{h}\left(\mathrm{~N} / \mathrm{mm}^{2}\right) ; \sigma_{3}=0.37 f_{R, 4} \kappa_{h}\left(\mathrm{~N} / \mathrm{mm}^{2}\right) ;$

$E_{c}=9500\left(f_{f c m}\right)^{1 / 3}\left(\mathrm{~N} / \mathrm{mm}^{2}\right) ; \varepsilon_{1}=\sigma_{1} / E_{c} ; \varepsilon_{2}=\varepsilon_{1}+0.1 \% 0 ; \varepsilon_{3}=25 \% 0$

Fig. 3. Stress-Strain relationship for FRC

Where $d$ is distance from top of the section to reinforcement bar (equal to section height in case of no reinforcement bar), $\kappa_{h}$ is size factor, $f_{f c m}$ is the mean 28-day compressive strength, $f_{f c t m, f l}$ is the mean flexural tensile strength, $f_{R, 1}$ and $f_{R, 4}$ are residual flexural tensile strength values. Detailed discussion on these parameters and their method of derivation is available in RILEM [29].

Table 5. Failure loads for 3-point bending tests

\begin{tabular}{llll}
\hline Mix & Micro steel fiber ratio (\%) & Macro steel fiber ratio (\%) & Failure load (tonf) \\
\hline 1 & - & 0.5 & 1.47 \\
2 & 0.5 & - & 2.12 \\
3 & 0.3 & 0.3 & 1.84 \\
4 & 0.5 & 0.5 & 2.16 \\
5 & 0.3 & 0.5 & 1.85 \\
6 & 0.5 & 0.3 & 1.89 \\
\hline
\end{tabular}

Table 6. Mean values for $f_{\max }, f_{r i}(\mathrm{i}=1-4)$ (in $\left.\mathrm{MPa}\right)$ and $C V(\%)$

\begin{tabular}{|c|c|c|c|c|c|c|}
\hline Mix No. & Mix. Abbrev. & $f_{\max } / \mathrm{CV}$ & $f_{r 1} / C V$ & $f_{r 2} / C V$ & $f_{r 3} / \mathbf{C V}$ & $f_{r 4} / C V$ \\
\hline 1 & $0.5 \mathrm{Mac}$ & $4.2 / 3.2$ & $3.3 / 3.5$ & $3.2 / 8.4$ & $2.5 / 7.7$ & $2.4 / 8.1$ \\
\hline 2 & $0.5 \mathrm{Mic}$ & $6.0 / 4.1$ & $4.0 / 4.6$ & $5.2 / 7.2$ & $4.0 / 11.1$ & $3.0 / 11.3$ \\
\hline 3 & 0.3Мас0.3Mic & $5.2 / 3.7$ & $4.9 / 4.1$ & $4.2 / 8.3$ & 2.9/9.1 & $2.0 / 7.6$ \\
\hline 4 & 0.5Mac0.5Mic & $6.1 / 5.1$ & $5.7 / 5.9$ & 4.7/12.1 & $4.2 / 18.8$ & $3.4 / 15.2$ \\
\hline 5 & 0.5Mac0.3Mic & $5.3 / 2.8$ & $3.9 / 3.3$ & 3.0/6.5 & $2.5 / 8.1$ & 2.0/9.2 \\
\hline 6 & 0.3Mac0.5Mic & $5.4 / 4.7$ & $5.0 / 4.4$ & 4.3/8.9 & $3.3 / 7.7$ & $2.9 / 8.7$ \\
\hline
\end{tabular}

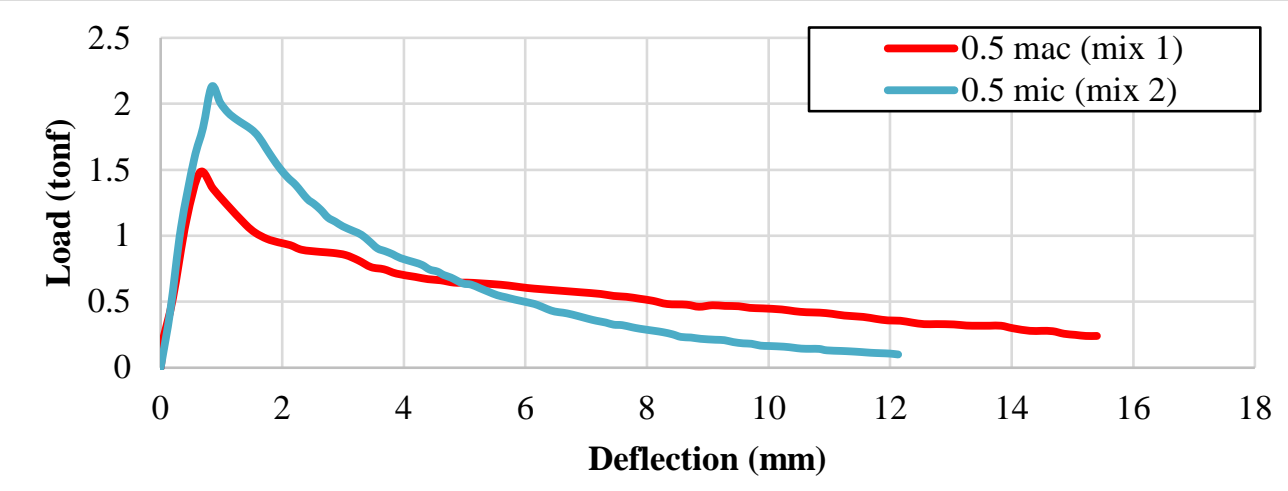

Fig. 4. Load-deflection curve for mix 1 and mix 2. 


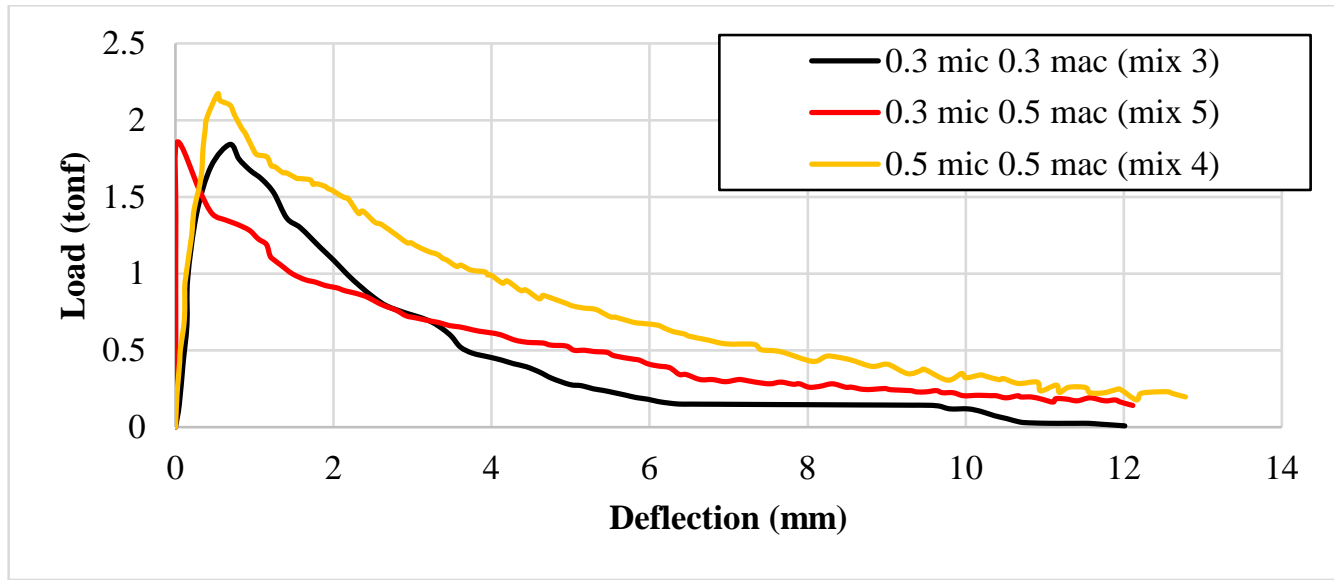

Fig. 5. Load-deflection curve for mix 3, mix 5 and mix 4.

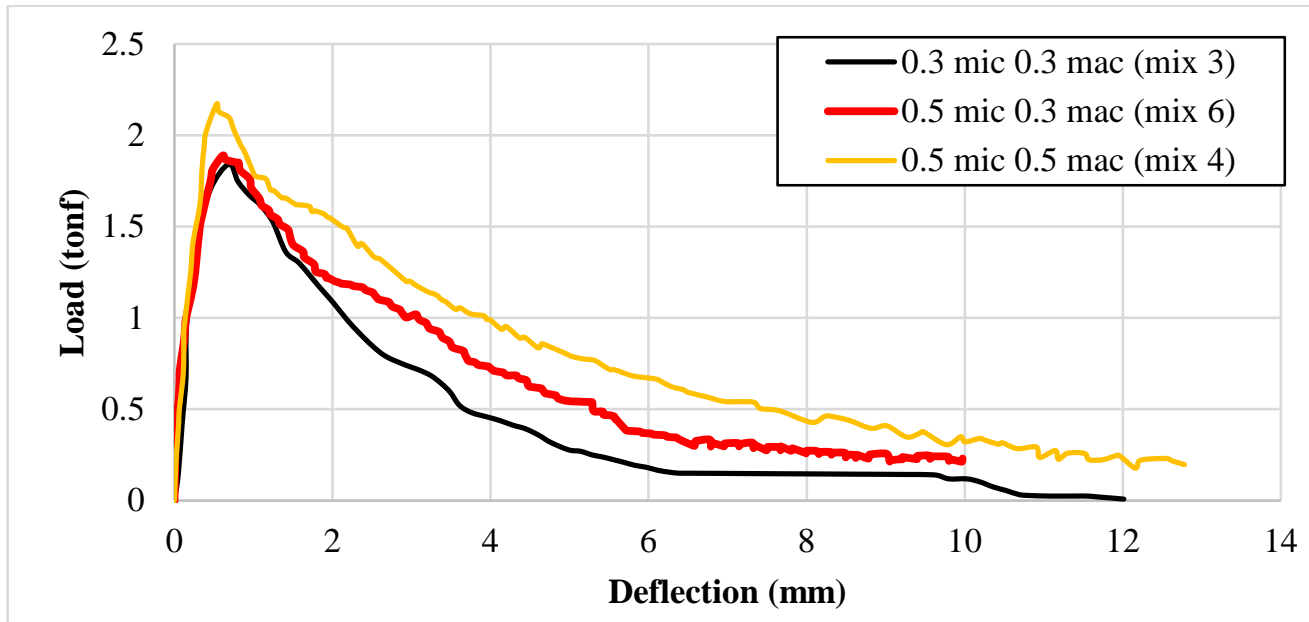

Fig. 6. Load-deflection curve for mix 3, mix 6 and mix 4.

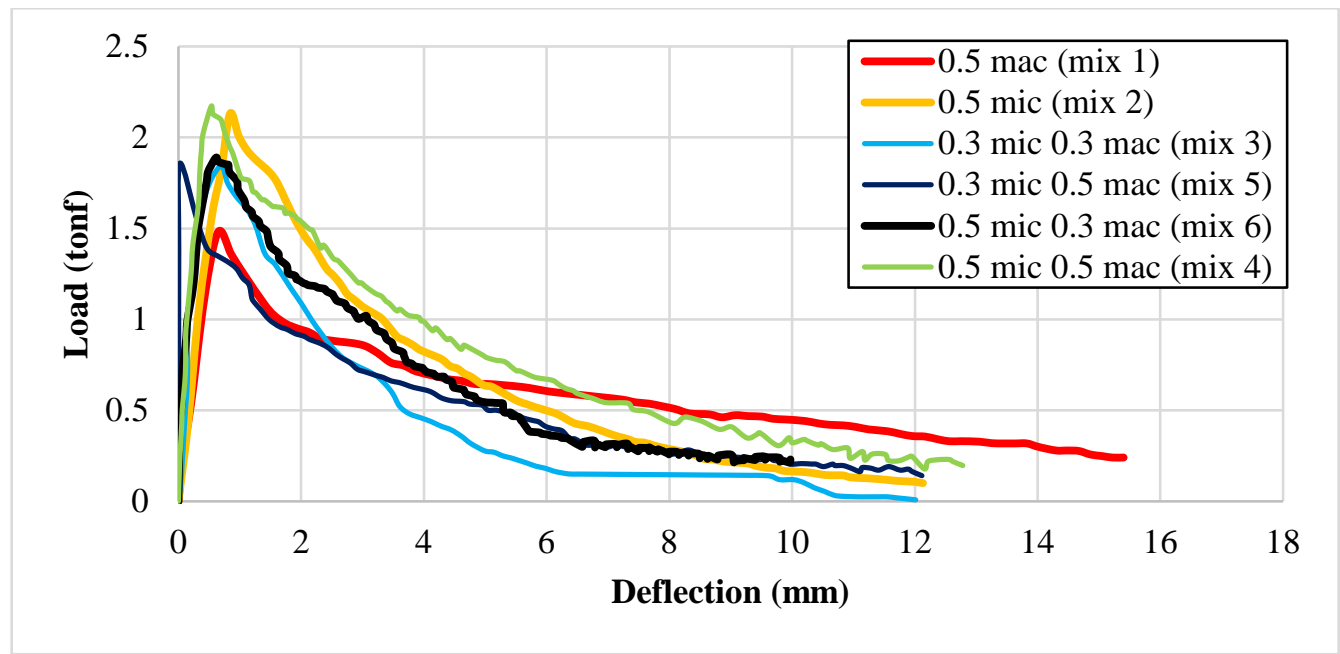

Fig. 7. Load deflection curve for all concrete mixes

By adding 0.5\% micro fibers (concrete mix 2), the failure load is around 0.65tonf (about 44\%) higher than the mix with the same dosage of macro fibers, i.e. concrete mix 1.

For a constant dosage of $0.5 \%$ macro fiber, adding micro fibers up to $0.5 \%$ of volume content causes a failure load increase of about $47 \%$. While for the same dosage of micro fiber kept constant in a mix, a $0.5 \%$ addition of macro fibers leads to only $2 \%$ rise in failure load. Moreover, by comparing mix 2 with mix 4, and mix 3 with mix 
5 , the failure load shows little increase with the addition of macro fibers. The results clearly indicate the more beneficial role of micro fibers over macro fibers in enhancing the flexural strength in hybrid composites.

By comparing residual post-crack flexural strength and toughness of different hybrid mixes, hooked end macro size fibers have a more distinct influence in increasing the post-crack properties of concrete than flattened end micro size fibers (especially in larger deflections). This can be put to the fact that in the post-crack region, where cracks tend to expand and open up, macro size hooked end fibers create a more effective bridging mechanism to limit crack propagation, due to their greater length and hooked shaped ends.

\subsection{Stress-strain relationships for hybrid SFRC}

After estimating the mean and residual flexural tensile strength values from load-deflection relationships, the tensile stress-strain constitutive relationships for each SFRC mix is derived using the RILEM approach and presented in Table 7.

Table 7. Tensile $\sigma-\varepsilon$ relationship of the SFRC composites

\begin{tabular}{llllllll}
\hline $\begin{array}{l}\text { Mix } \\
\text { No. }\end{array}$ & Mix Abbrev. & $\begin{array}{l}\boldsymbol{\sigma} \mathbf{1} \\
\text { (Mpa) }\end{array}$ & $\begin{array}{l}\boldsymbol{\sigma 2} \\
\text { (Mpa) }\end{array}$ & $\begin{array}{l}\boldsymbol{\sigma 3} \\
\text { (Mpa) }\end{array}$ & $\begin{array}{l}\mathbf{\varepsilon 1} \\
(\mathbf{\% o})\end{array}$ & $\begin{array}{l}\mathbf{\varepsilon 2} \\
(\%)\end{array}$ & $\begin{array}{l}\mathbf{\varepsilon 3} \\
(\%)\end{array}$ \\
\hline 1 & 0.5 Mac & 6.31 & 5.23 & 2.58 & 0.192 & 0.292 & 25 \\
2 & 0.5 Mic & 8.54 & 7.87 & 2.96 & 0.223 & 0.323 & 25 \\
3 & 0.3 Mac0.3Mic & 7.31 & 6.74 & 1.76 & 0.206 & 0.306 & 25 \\
4 & 0.5 Mac0.5Mic & 7.73 & 5.75 & 3.68 & 0.212 & 0.312 & 25 \\
5 & 0.5 Mac0.3Mic & 7.82 & 5.82 & 2.44 & 0.213 & 0.313 & 25 \\
6 & 0.3 Mac0.5Mic & 7.03 & 6.03 & 2.86 & 0.202 & 0.302 & 25 \\
\hline
\end{tabular}

\section{Numerical validation of stress-strain relationships for hybrid SFRC}

In the previous section, the fundamental $\sigma-\varepsilon$ relationships of the SFRC composites were obtained based on RILEM guidelines. This guideline is originally developed for non-hybrid SFRC and its capability in characterizing $\sigma-\varepsilon$ relationships for hybrid SFRC is not proven. In this regard, the 3PBT for each of the hybrid SFRC composites is simulated using a numerical model. Resultant load-deflection curves from the numerical models are then compared to that of the actual 3PBT experiments to verify the stress-strain models.

The ABAQUS Finite Element (FE) software was used to develop 3D models of the beam using 3D stress hex elements (Figure 8) [30] with suitable mesh sizes in the longitudinal, transverse and thickness directions (obtained using a limited sensitivity analysis). The FE model captured the main features of the 3PBTs, including beam geometry, properties, and simple support conditions. The Concrete Damaged Plasticity (CDP) [31] model was employed to adequately replicate the SFRC material behavior. The obtained $\sigma-\varepsilon$ values the for hybrid SFRC composites are assigned to the beams. A dynamic solver is used in the analysis to consider loading rate effects.
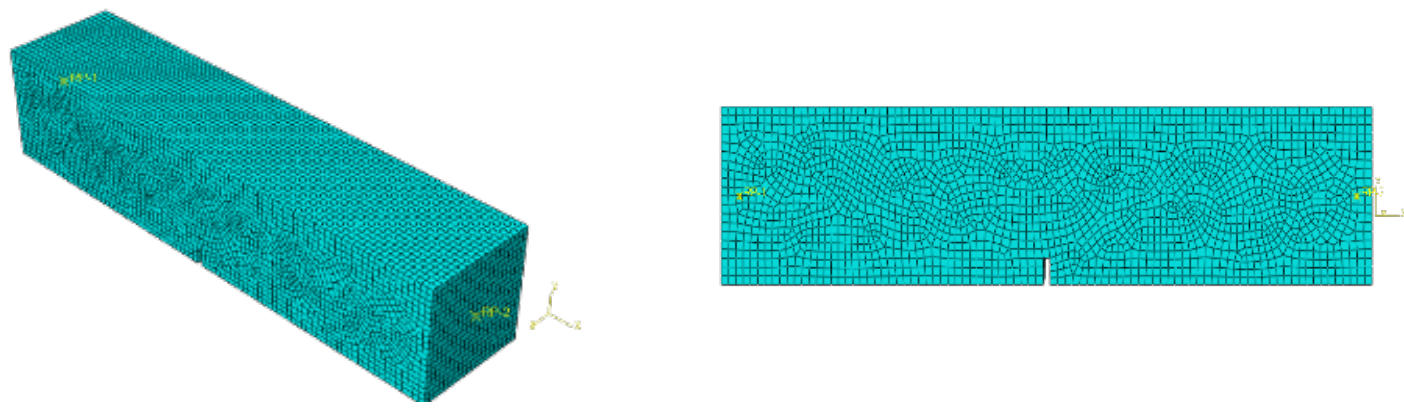

Fig. 8. FE model of 3PBT beams

In Figures 9-12, load vs. deflection values, resulting from the numerical and experimental campaigns are plotted together. Maximum applied load $\left(F_{\max }\right)$ and load values corresponding to $f_{r i}, i=1-4$, for the numerical and experimental cases, along with relative error $(\delta)$ values, are tabulated in Table 8 . It can be observed that in all hybrid composites, the Fmax values of experiment are well predicted by the numerical modeling $(\delta<14 \%)$. The deflection values at ultimate capacity deviates slightly from that of experimental results. As for $f_{r i}$, higher discrepancies (up to around 38\%) can be seen between the experimental and numerical results. Therefore, in the post-crack region, the numerical results generally show moderately higher strength values than experiment, yet 
considered within acceptable tolerance. In line with past research, the FE model generally overestimates experimental values [32].

Table 8. Numerical (ABQ) and Experimental(EXP) values of $F_{\max }, F_{r 1}, F_{r 2}, F_{r 3}(\mathrm{kN})$ and relative errors, $\delta$ (\%)

\begin{tabular}{|c|c|c|c|c|c|c|c|c|c|c|}
\hline \multirow{2}{*}{$\begin{array}{l}\text { Hybrid Mix } \\
\text { Abbrev. }\end{array}$} & \multicolumn{2}{|l|}{$\mathbf{F}_{\max }$} & \multicolumn{2}{|l|}{$\mathbf{F}_{\mathbf{r} 1}$} & \multicolumn{2}{|l|}{$\mathbf{F}_{\mathbf{r} 2}$} & \multicolumn{2}{|l|}{$F_{\mathbf{r} 3}$} & \multicolumn{2}{|l|}{$F_{r 4}$} \\
\hline & ABQ/EXP & $\delta(\%)$ & $\mathrm{ABQ} / \mathrm{EXP}$ & $\delta(\%)$ & $\mathrm{ABQ} / \mathrm{EXP}$ & $\delta(\%)$ & ABQ/EXP & $\delta(\%)$ & ABQ/EXP & $\delta(\%)$ \\
\hline $0.3 \mathrm{Mac} 0.3 \mathrm{Mic}$ & $1.95 / 1.84$ & 5.6 & 1.91/1.61 & 15.7 & 1.10/1.11 & 0.9 & 0.95/0.77 & 18.9 & $0.82 / 0.51$ & 37.8 \\
\hline 0.5Mac0.5Mic & $2.47 / 2.17$ & 12.1 & $2.44 / 1.85$ & 24.2 & $1.79 / 1.59$ & 11.2 & $1.40 / 1.31$ & 6.4 & $1.23 / 1.07$ & 13.0 \\
\hline 0.5Mac0.3Mic & $1.90 / 1.86$ & 2.1 & $1.89 / 1.36$ & 28.0 & $1.30 / 1.07$ & 17.7 & $1.06 / 0.88$ & 17.0 & 0.93/0.72 & 22.6 \\
\hline $0.3 \mathrm{Mac} 0.5 \mathrm{Mic}$ & $2.06 / 1.89$ & 8.3 & 2.06/1.66 & 19.4 & $1.25 / 1.24$ & 0.8 & $1.09 / 1.08$ & 0.9 & $1.02 / 0.82$ & 19.6 \\
\hline
\end{tabular}

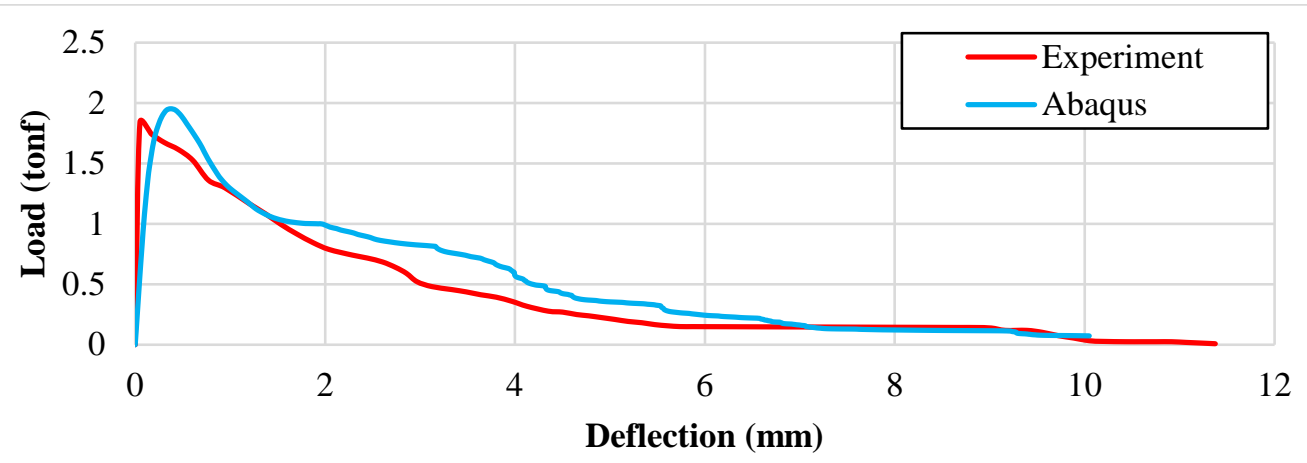

Fig. 9. Load-deflection curves for 0.3mic 0.3mac (mix 3): Experimental and Finite element results

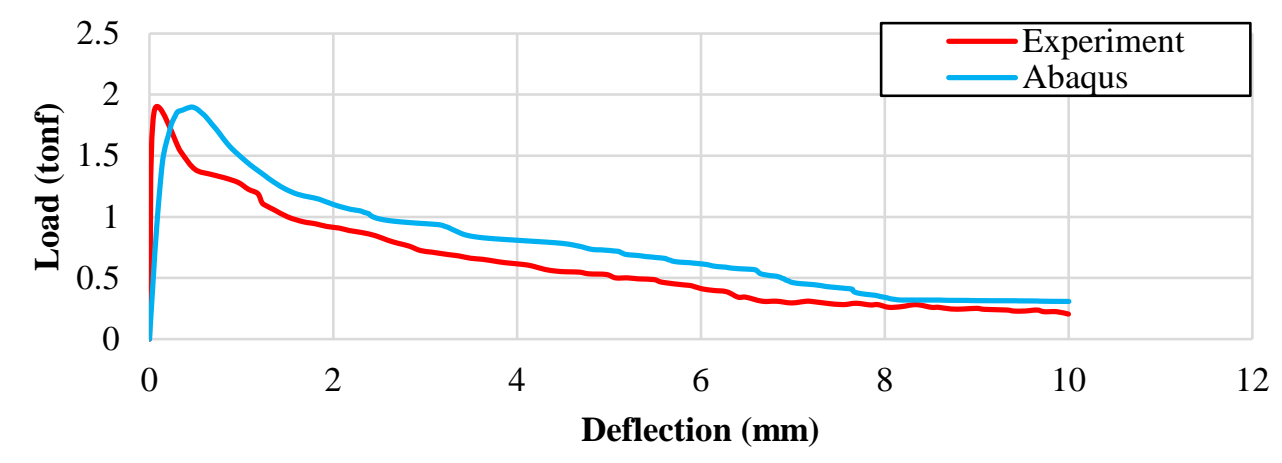

Fig. 10. Load-deflection curves for 0.3mic 0.5mac (mix 5): Experimental and Finite element results

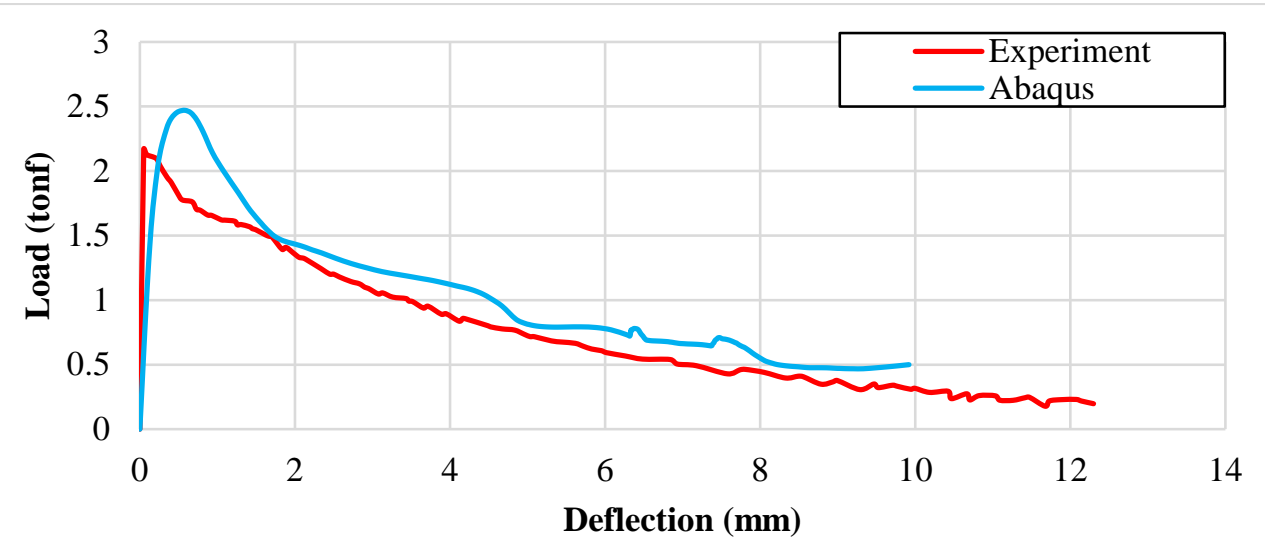

Fig. 11. Load-deflection curves for 0.5mic 0.5mac (mix 4): Experimental and Finite element results. 


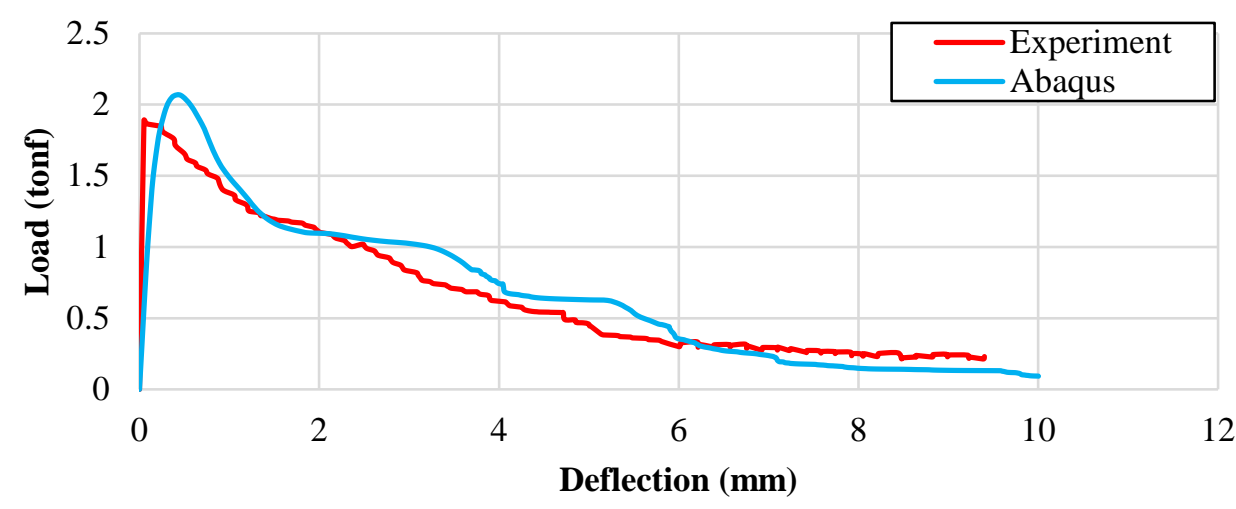

Fig. 12. Load-deflection curves for 0.5mic 0.3mac (mix 6): Experimental and Finite element results

\section{Conclusions}

The aim of this paper was to investigate and validate constitutive material models, derived from the RILEM guidelines, for hybrid SFRC concrete, comprised of different types of steel fibers. To this end, basic engineering properties of hybrid SFRC composites were determined using compressive, splitting tensile and 3PBTs tests. To validate results, numerical tests were performed using the finite element approach. The main experimental and numerical results are summarized as below:

Both micro and macro size steel fibers increase the compressive and tensile strength of concrete mixes compared to plain concrete, though micro size fibers being more effective. These beneficial effects are more obvious for hybrid composites.

For equal amounts of macro and micro sized steel fibers, the latter has a greater influence on enhancing the ultimate load capacity of hybrid SFRC composites.

Micro fibers are more effective than macro fibers in increasing the flexural strength of hybrid composites. On the other hand, by comparing residual post-crack flexural strength and toughness of different hybrid mixes, hooked end macro size fibers have a more distinct influence in increasing the post-crack properties of concrete than flattened end micro size fibers (especially in larger deflections). Thus, micro fibers activate before the macro fibers.

FE models can well predict experimental results, especially ultimate load capacity values. The deflection values at ultimate capacity deviates slightly from that of experimental results. In the post-crack region, the numerical results generally show moderately higher strength values than experiment.

Both Micro and Macro size steel fibers generally improve various engineering properties of concrete, despite advantages of one on the other for different mechanical properties. Under flexural load, micro size fibers are activated at an earlier stage, while macro size fibers have a more distinct influence in increasing the post-crack performance. This is due to their better bridging mechanism in the concrete composite (especially in larger deflections). Thus, to take full advantage, hybridization is a more preferable option. The tri-linear stress-strain relationship, originally proposed for SFRC by RILEM, has showed to yield acceptable results for characterizing the behavior of hybrid SFRC composites. Therefore, hybridization can be considered an available option for practical design purposes, such as tunnel lining segments.

\section{Acknowledgements}

The authors would like to appreciate the support of the Construction Materials Institute (CMI) and the Structural Testing Laboratory of the Civil Engineering Department, University of Tehran.

\section{References}

[1] Mobasher B. Mechanics of fiber and textile reinforced cement composites. CRC press; 2011.

[2] Hannant DJ. Fiber cements and fiber concrete. Chichester, UK: John Wiley \& Sons; 1978.

[3] Monfore GE. A review of fiber reinforcement of Portland cement paste, mortar, and concrete. Journal Pca Res \& Dev Laboratories. 1968.

[4] Fédération Internationale Du Béton (FIB). Model code 2010. In: FIB Bulletins 65-66 (2010). Lausanne, Switzerland; 2010.

[5] RILEM TC. $\sigma-\varepsilon$ design method-final recommendation. Materials and Structures. 2003; 36: 560-570. 
[6] American Concrete Institute (ACI). 544 Committee report on fiber reinforced concrete. 1988.

[7] Sorelli LG, Meda A, Plizzari GA. Bending and uniaxial tensile tests on concrete reinforced with hybrid steel fibers. Journal of Materials in Civil Engineering. 2005;17(5):519-527.

[8] Ganesan N, Indira PV, Irshad P. RCC frames with ferrocement and fiber reinforced concrete infill panels under reverse cyclic loading. Advances in Concrete Construction. 2017;5(3):257-270.

[9] Su Y, Li J, Wu C, Wu P, Tao M, Li X. Mesoscale study of steel fibre-reinforced ultra-high performance concrete under static and dynamic loads. Materials \& Design. 2017;116:340-351.

[10] Avanaki MJ, Hoseini A, Vahdani S, de Santos C, de la Fuente A. Seismic fragility curves for vulnerability assessment of steel fiber reinforced concrete segmental tunnel linings. Tunnelling and Underground Space Technology. 2018;78:259-274.

[11] Avanaki MJ, Hoseini A, Vahdani S, de la Fuente A. Numerical-aided design of fiber reinforced concrete tunnel segment joints subjected to seismic loads. Construction and Building Materials. 2018;170:40-54.

[12] Kasper T, Edvardsen C, Wittneben G, Neumann D. Lining design for the district heating tunnel in Copenhagen with steel fibre reinforced concrete segments. Tunnelling and Underground Space Technology. 2008;23(5):574-587.

[13] Caratelli A, Meda A, Rinaldi Z, Romualdi P. Structural behaviour of precast tunnel segments in fiber reinforced concrete. Tunnelling and Underground Space Technology. 2011;26(2):284-291.

[14] De la Fuente A, Pujadas P, Blanco A, Aguado A. Experiences in Barcelona with the use of fibres in segmental linings. Tunnelling and Underground Space Technology. 2012;27(1):60-71.

[15] Buratti N, Ferracuti B, Savoia M. Concrete crack reduction in tunnel linings by steel fibre-reinforced concretes. Construction and Building Materials. 2013;44:249-259.

[16] Chiaia B, Fantilli AP, Vallini P. Combining fiber-reinforced concrete with traditional reinforcement in tunnel linings. Engineering Structures. 2009;31(7):1600-1606.

[17] Jamshidi Avanaki M, Abedi M, Hoseini A. Experimental and numerical-based design of hybrid steel fibrereinforced concrete tunnels. Magazine of Concrete Research. 2019.

[18] Caggiano A, Folino P, Lima C, Martinelli E, Pepe M. On the mechanical response of hybrid fiber reinforced concrete with recycled and industrial steel fibers. Construction and Building Materials. 2017;147:286-295.

[19] Meda A, Rinaldi Z, Caratelli A, Cignitti F. Experimental investigation on precast tunnel segments under TBM thrust action. Engineering structures. 2016;119:174-185.

[20] Mobasher B, Li CY. Mechanical properties of hybrid cement-based composites. ACI Materials Journal. 1996;93:284-292.

[21] Libre NA, Shekarchi M, Mahoutian M, Soroushian P. Mechanical properties of hybrid fiber reinforced lightweight aggregate concrete made with natural pumice. Construction and Building Materials. 2011;25(5):2458-2464.

[22] Alberti MG, Enfedaque A, Gálvez JC. Fibre reinforced concrete with a combination of polyolefin and steelhooked fibres. Composite Structures. 2017;171:317-325.

[23]Zarrin O, Khoshnoud HR. Experimental investigation on self-compacting concrete reinforced with steel fibers. Structural Engineering and Mechanics. 2016;59(1):133-151.

[24] Nehdi ML, Najjar MF, Soliman AM, Azabi TM. Novel steel fibre-reinforced preplaced aggregate concrete with superior mechanical performance. Cement and Concrete Composites. 2017;82:242-251.

[25] Plizzari GA, Tiberti G. Steel fibers as reinforcement for precast tunnel segments. Tunnelling and Underground Space Technology. 2006;21(3):438-439.

[26] ASTM C496. Standard test method for splitting tensile strength of cylindrical concrete specimens; 1998.

[27] ASTM C39-96. Standard test method for compressive strength of cylindrical concrete specimens; 1998.

[28] RILEM TC. Bending test. Materials and Structures. 2002;35(9):579-582.

[29] Koyama Y. Present status and technology of shield tunneling method in Japan. Tunnelling and Underground Space Technology. 2003;18(2-3):145-159.

[30] DSSC. Abaqus v. 6.13 [Software]. Providence, RI: Dassault Systèmes Simulia Corp. 2012.

[31] DSSC. Abaqus/Standard 6.13 user's maunal. Providence, RI: Dassault Systèmes Simulia Corp. 2012.

[32] Blanco A, Pujadas P, De la Fuente A, Cavalaro S, Aguado A. Application of constitutive models in European codes to RC-FRC. Construction and Building Materials. 2013;40:246-259.

(C) 2020 by the author(s). This work is licensed under a Creative Commons Attribution 4.0 International License (http://creativecommons.org/licenses/by/4.0/). Authors retain copyright of their work, with first publication rights granted to Tech Reviews Ltd. 